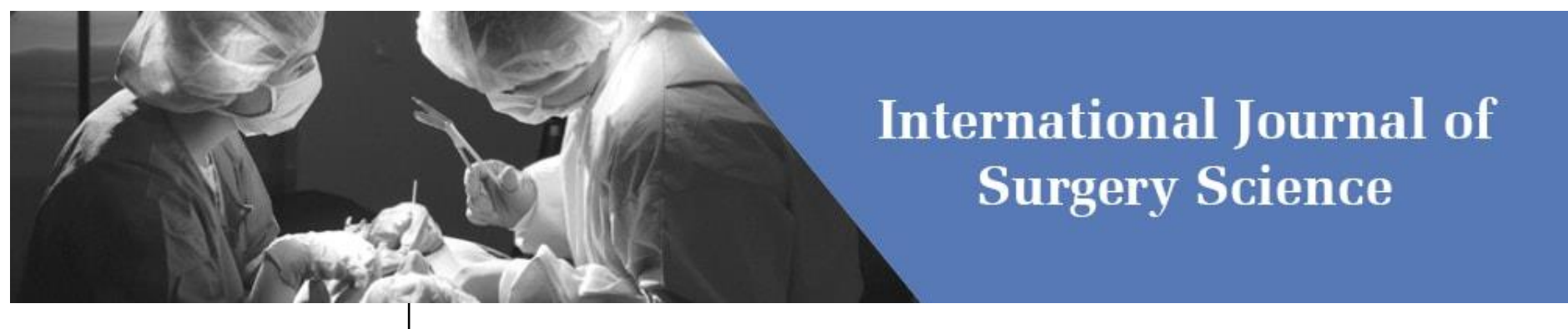

E-ISSN: 2616-3470

P-ISSN: 2616-3462

(C) Surgery Science

www.surgeryscience.com

2019; 3(4): 86-91

Received: 16-08-2019

Accepted: 20-09-2019

Venu Madhav Thumma

Associate professor, Department of Surgical Gastroenterology, Nizam's

Institute of Medical Sciences,

Hyderabad, Telangana, India

Surya Rama Chandra Varma

Gunturi

Department of Surgical

Gastroenterology, Nizam's

Institute of Medical Sciences,

Hyderabad, Telangana, India

Nava Kishore K

Department of Surgical

Gastroenterology, Nizam's

Institute of Medical Sciences,

Hyderabad, Telangana, India

Jagan Mohan Reddy B

Department of Surgical

Gastroenterology, Nizam's

Institute of Medical Sciences,

Hyderabad, Telangana, India

\section{N Bheerappa}

Department of Surgical

Gastroenterology, Nizam's

Institute of Medical Sciences,

Hyderabad, Telangana, India

Corresponding Author:

Venu Madhav Thumma

Associate professor, Department of

Surgical Gastroenterology, Nizam's

Institute of Medical Sciences,

Hyderabad, Telangana, India

\section{Surgery for liver tumors that are close to major vascular structures of future liver remnant}

\author{
Venu Madhav Thumma, Surya Rama Chandra Varma Gunturi, Nava \\ Kishore K, Jagan Mohan Reddy B and N Bheerappa
}

DOI: https://doi.org/10.33545/surgery.2019.v3.i4b.222

\section{Abstract}

Introduction: In patients with just enough future liver remnant (FLR) parenchymal transection preserving all the inflow or venous outflow of FLR is very important. Tumors close to the major hilar vessels or to the outflow of FLR pose unique challenges for assessment of resectability. In both benign and malignant conditions which are close to major vessels of FLR meticulous surgery is required to obtain good outcomes. Hence, we looked at the data of such tumors which are close to the inflow and outflow of FLR and studied the surgical feasibility and perioperative outcomes.

Aim: The aim of the present study was to study the perioperative results of resection of tumors close to the inflow or outflow of future liver remnant.

Material and methods: The study was a retrospective study conducted in the Department of Surgical Gastroenterology, Nizam's Institute of Medical Sciences, Hyderabad between 2015 to 2018. All tumors of the liver which were close $(<1 \mathrm{~cm})$ to the inflow or outflow of the FLR were included in the study. Both benign and malignant tumors close to major vasculature of FLR were included. The surgical feasibility, complications and R0 resection rate was studied. Intraoperative and postoperative complications were studied.

Results: Twenty three patients were included in the study. The mean age of the patients was $43.8(8-68)$ yrs. There were 8 patients with tumors close to outflow, 9 to inflow and 6 to both inflow and outflow of FLR. Preoperatively the diagnosis was benign in $6(6 / 23,26 \%)$. They were included in the study because of their critical location and proximity to the vasculature of FLR. Seven patients had a large SOL in liver $(>9 \mathrm{~cm})$. One patient underwent 2 stage hepatectomy because of hemodynamic instability. The final histopathology was HCC in 4, Hepatoblastoma 1, Adenoma 1 and Tuberculosis in 1. Seven patients with hilar mass underwent surgery (3 had hilar cholangiocarcinoma, 1 intrahepatic cholangiocarcinoma and 3 benign). Segmentectomy was done in 3 (1 colorectal liver metastasis, 2 HCC with CLD)

The final biopsy was malignancy in 12 patients. Two $(2 / 12,16.6 \%)$ of them had a positive resection margin). Five patients $(5 / 17,29 \%)$ with preoperative suspicion of malignancy had a benign etiology (1 adenoma, 2 tuberculosis, 2 granular cell tumor) on final histopathology. There was $1(1 / 23,4.3 \%)$ mortality in our series due to bile leak and fungal sepsis. Two patients had transient liver failure (Grade II). Six (5 Grade II, 1 Grade V) patients had transient bile leak.

Conclusion: Tumors close to inflow or outflow of FLR can be resected with acceptable morbidity and mortality.

Keywords: Future liver remnant, resection margin, tumor near inflow or outflow

\section{Introduction}

Hepatic resection can safely be done if the tumor can be removed by preserving the inflow through arterial and portal venous system without compromising the outflow of an adequate future liver remnant (FLR). However, when assessing the resectability of liver tumors, several challenges can be faced. When the FLR is low techniques like portal vein embolization ${ }^{[1]}$ can be used to increase the FLR. However, when FLR is just enough parenchymal transection preserving all the inflow or venous outflow of FLR is very important. Tumors close to the major hilar vessels or to the outflow of FLR pose unique challenges for assessment of resectability. One of the main problems of these tumors are obtaining a negative margin. In ideal conditions the distance between the tumor edge and margin should be about $1 \mathrm{~cm}^{[2]}$. In tumors close to the inflow or outflow obtaining a $1 \mathrm{~cm}$ margin is difficult.

The incidence of vascular invasion is higher in large hepatocellular carcinomas (HCC) ${ }^{[3]}$. However In the absence of other treatment options that can produce comparable long term 
survival results, it appears reasonable to consider hepatic resection as the treatment of choice for HCC larger than $10 \mathrm{cms}^{4}$.In study by Poon et al. ${ }^{[4]} 3.5 \%$ had macroscopic residual disease when resection was attempted. However, the survival was reasonable when curative resection was achieved which was as complete macroscopic removal of the tumor ${ }^{[4]}$.

A positive surgical margin is more likely to be associated with tumors that are centrally located and are closely adjacent to a major vessel ${ }^{[3,5]}$. It is occasionally not possible to define an adequate surgical margin and simultaneously preserve enough liver parenchyma ${ }^{[5]}$. The effect of the surgical margin on HCC recurrence after resection of large HCCs is controversial ${ }^{[5]}$.

It is possible that tumor invasiveness, and not solely the section margin, determines the long-term prognosis of large HCCs. An expert meeting on resection of large HCCS suggested resection by majority even when $\mathrm{R} 1$ resection is a possibility ${ }^{[5]}$. In colorectal liver metastasis complete resection with close margin is still associated with improved survival ${ }^{[6,7]}$. Indeed, margin distance is often sacrificed when patient safety may be threatened or to preserve major vascular structures that may lie in proximity to the FLR ${ }^{[8]}$.

It is also important to know that pushing and hanging tumors are resectable as opposed to tumors with irregular margins which can be invasive. In addition to malignant tumors some benign conditions also pose challenges. Large biliary cystadenomas are centrally located and are usually close to inflow and outflow of FLR. Likewise, giant symptomatic haemangiomas can be close to major vessels of FLR. In both benign and malignant conditions meticulous surgery is required to prevent injury to major vessels of FLR. Hence, we looked at the data of such tumors which are close to the inflow and outflow of FLR and studied the surgical feasibility and perioperative outcomes.

\section{Aim}

The aim of the present study was to study the perioperative results of resection of tumors close to the inflow or outflow of future liver remnant.

\section{Material and methods}

The study was a retrospective study conducted in the Department of Surgical Gastroenterology, Nizam's Institute of Medical Sciences, Hyderabad between 2015 to 2018. All resections were done by a single surgeon who works in a high volume center.

\section{Inclusion criteria}

1. All tumors of the liver which were close $(<1 \mathrm{~cm})$ to the inflow or outflow of the future liver remnant were included in the study

2. Both benign and malignant tumors close to major vasculature of FLR were included.

\section{Exclusion criteria}

1. Tumors that are infiltrating the inflow or outflow of FLR based on imaging were excluded from the study

2. Patients with inadequate FLR

All patients with liver tumors were evaluated by CECT triphasic abdomen. The relation of the tumors with the major vessels was carefully studied. The volume of FLR was estimated by CT scan. In patients with inadequate FLR portal vein embolization was considered. However, when patients with FLR was just adequate and the tumor was close to the major vessels of FLR resection was attempted. FLR was considered adequate if it is more than $20 \%$ of total liver volume in normal livers and more than $40 \%$ of total liver volume in patients with chronic liver disease (Child A).

Patients with large lesions (HCC, Adenoma etc.) close to right hepatic vein (RHV), middle hepatic vein (MHV) and/or left hepatic vein (LHV) were included. Patients with perihilar tumors close to inflow of FLR were also included. In patients with obstructive jaundice preoperative biliary drainage was done to decrease the bilirubin levels to $<5 \mathrm{mgms} \%$. Also, patients with cholangitis were treated before considering for resections.

\section{Surgery}

All patients underwent surgery with Right subcostal incision. A thoracoabdominal approach was considered for very large tumors and when access to outflow was compromised. In large tumors of the liver initial inflow vessels were dissected. The hepatic artery and portal vein were looped. Then if possible, outflow control was taken. In very large tumors suprahepatic IVC control was obtained if required. The inflow vessels were ligated only after parenchymal transection was done. If required intermittent pringle manoeuvre was done. Parenchymal transection was done with CUSA. The tumor was carefully separated from outflow (MHV, RHV or LHV). If during parenchymal transection if any compromise happens to outflow of FLR or hemodynamic changes occur the plan was to perform a rescue ALPSS or two stage hepatectomy if feasible. For perihilar tumors the lower end of bile duct was cut. Then the inflow to the FLR was assessed. If required a vascular resection was considered. After inflow and outflow control parenchymal transection was performed.

The surgical feasibility, complications and $\mathrm{R} 0$ resection rate was studied. Intraoperative and postoperative complications were studied.

\section{Results}

Twenty three patients were included in the study. The mean age of the patients was $43.8(8-68)$ yrs. There were 8 patients with tumors close to outflow, 9 to inflow and 6 to both inflow and outflow of FLR.

\section{Tumors close to the outflow of FLR}

There were 8 tumors which were close to the outflow of FLR. All were more than $9 \mathrm{~cm}$ in size. The surgeries done were Right hepatectomy in 3 (partial MHV resection 2), Right trisectionectomy in 2, Left hepatectomy in 1 and Central hepatectomy in 2. All patients underwent inflow control and outflow control. However, the inflow was ligated and cut only after parenchymal transection. One patient had hemodynamic instability after parenchymal transection, hence was taken up for 2 stage hepatectomy. The mean blood loss was $800 \mathrm{ml}$. Two patients had transient liver failure (Grade II) and recovered. Three had bile leak (2 grade II, 1 Grade V) of which 2 patients recovered. One patient had bile leak and fungal sepsis. She died after 1 month due to fungal sepsis. One patient with hepatoblastoma had a resection margin which was positive. 
Table 1: Tumors close to the outflow of FLR

\begin{tabular}{|c|c|c|c|c|c|}
\hline Sl. No & Diagnosis & Vessel & Size & Surgery & HPE \\
\hline 1 & HCC Right LOBE & MHV & $10.9 \times 8.3 \times 10.6 \mathrm{~cm}$ & Rt hepatectomy & Well differentiated HCC \\
\hline 2 & SOL left lobe & MHV & $10 \mathrm{x} 8 \mathrm{~cm}$ & Left hepatectomy & Tuberculosis \\
\hline 3 & SOL rt lobe & MHV & $9 \times 6 \mathrm{~cm}$ & Rt hepatectomy & Adenoma \\
\hline 4 & HCC Right lobe & MHV & $7 \times 9 \mathrm{~cm}$ & Rt hepatectomy & $\mathrm{HCC}$ \\
\hline 5 & $\begin{array}{l}\text { Hepatoblastoma } \\
\text { (Fig 1) }\end{array}$ & $\begin{array}{l}\text { Diaphragm, } \\
\text { LHV }\end{array}$ & $\begin{array}{l}12 \times 11 \times 13 \text { seg } 8,7,4 a \\
\text { indenting MHV and LHV }\end{array}$ & Rt trisectionectomy with cuff of diaphragm & Hepatoblastoma \\
\hline 6 & SOL rt lobe & LHV & $20 \times 16 \mathrm{~cm}$ & $\begin{array}{l}2 \text { stage initial parenchymal transection followed by } \\
\text { portal vein ligation } 2 \text { nd stage right trisectionectomy }\end{array}$ & $\mathrm{HCC}$ \\
\hline 7 & SOL rt lobe & RHV, LHV & $8.6 \times 9 \mathrm{~cm}$ & Central hepatectomy & Biliary cystadenoma \\
\hline 8 & SOL rt lobe & RHV, LHV & $9 X 9 \mathrm{~cm}$ & Central hepatectomy & Biliary cystadenoma \\
\hline
\end{tabular}

\section{Tumors close to inflow of FLR}

The preoperative diagnosis and the surgeries performed were summarised in table 2 . The mean blood loss was $750 \mathrm{ml}$.Two patients had transient bile leak. There was no mortality in this group. One patient with hilar cholangiocarcinoma had radial margin positive.

Table 2: Tumors close to inflow of FLR

\begin{tabular}{|c|c|c|c|c|}
\hline Sl. No & Preop Diagnosis & \begin{tabular}{|c|} 
Structures \\
\end{tabular} & Surgery & HPE \\
\hline 1 & HCV with CLD with HCC Fig 5 & Rt posterior pedicle splayed & Seg 5 excision & $\mathrm{HCC}$ \\
\hline 2 & HCC seg 5,6 HBV with CLD & portal vein bifurcation & Seg 5,6 excision & $\mathrm{HCC}$ \\
\hline 3 & Hilar stricture & portal vein bifurcation & Rt hepatectomy & Granular cell tumor \\
\hline 4 & Hilar stricture & $\begin{array}{c}\text { portal vein bifurcation and } \\
\text { left artery }\end{array}$ & Rt hepatectomy & Tuberculosis \\
\hline 5 & $\begin{array}{c}\begin{array}{c}\text { Hilar cholangiocarcinoma with? } \\
\text { choledochal cyst }\end{array} \\
\end{array}$ & $\begin{array}{c}\text { portal vein bifurcation and } \\
\text { right artery }\end{array}$ & $\begin{array}{c}\text { Lt hepatectomy caudate lobe } \\
\text { excision, HJ }\end{array}$ & $\begin{array}{c}\text { Intraductal papillary neoplasm of bile duct } \\
\text { with mod dysplasia }\end{array}$ \\
\hline 6 & Hilar cholangiocarcinoma & left portal vein and artery & $\begin{array}{c}\text { Lt hepatectomy caudate lobe } \\
\text { excision HJ }\end{array}$ & $\begin{array}{l}\text { poorly differentiated hilar cholangiocarcinoma } \\
\text { Left duct radial margin positive }\end{array}$ \\
\hline 7 & Intrahepatic cholangiocarcinoma & left portal vein and artery & $\begin{array}{c}\text { left hepatectomy, caudate lobe } \\
\text { excision HJ }\end{array}$ & $\begin{array}{c}\text { Intraductal papillary neoplasm with invasive } \\
\text { carcinoma T2a No }\end{array}$ \\
\hline 8 & $\begin{array}{c}\text { choledochal cyst with hilar mass } \\
\text { Fig } 2\end{array}$ & portal vein bifurcation & $\begin{array}{l}\text { left hepatectomy caudate lobe } \\
\text { excision, HJ }\end{array}$ & $\begin{array}{c}\text { 6x2x1cm in CHD, LHD, RHD papillary } \\
\text { adenocarcinoma }\end{array}$ \\
\hline 9 & Hilar stricture & left artery & Rt hepatectomy & Granular cell tumor \\
\hline
\end{tabular}

Tumors close to inflow and outflow of FLR

The cases are summarized in Table 3. There was no mortality. One patient had transient bile leak.

Table 3: Tumors close to inflow and outflow of FLR

\begin{tabular}{|c|c|c|c|c|}
\hline Sl. No & Preoperative diagnosis & Vessels involved & Surgery & HPE \\
\hline 1 & Colorectal liver metastasis & RHV, MHV, Portal vein & segmentectomy 5,6 & Colorectal liver metastasis \\
\hline 2 & Hemangioma of liver & MHV, Portal vein bifurcation & Enucleation & Hemangioma \\
\hline 3 & HCC post PVE (Fig 3) & MHV, portal vein & Right trisectionectomy & HCC \\
\hline 4 & Giant hemangioma liver (Fig 4) & MHV, Portal vein bifurcation & left hepatectomy & Hemangioma \\
\hline 5 & Hemangioma & MHV, Portal vein bifurcation & Enucleation & Hemangioma \\
\hline 6 & Hemangioma left lobe initial surgery bleed later reexplored & MHV, Portal vein bifurcation & left hepatectomy & Hemangioma \\
\hline
\end{tabular}

Preoperatively the diagnosis was benign in $6(6 / 23,26 \%)$. Four had hemangioma, two had biliary cystadenoma. They were included in the study because of their critical location and proximity to the vasculature of FLR. We had a very giant hemangioma $(32 \times 24 \mathrm{~cm})$ occupying entire abdomen and reaching pelvis. She underwent left hepatectomy (Fig 4). One hemangioma had bleeding and hence packing was done. She was reexplored and underwent left hepatectomy after $48 \mathrm{hrs}$. Two patients with biliary cystadenoma underwent central hepatectomy.

Seven patients had a large SOL in liver $(>9 \mathrm{~cm})$. The final histopathology was HCC in 4, Hepatoblastoma 1, Adenoma 1 and Tuberculosis in 1. The procedures they underwent were Right trisectionectomy 2, Left trisectionectomy 1, Rt hepatectomy 3 (partial MHV resection 2) and left hepatectomy in 1. Seven patients with hilar mass underwent surgery (3 had hilar cholangiocarcinoma, 1 intrahepatic cholangiocarcinoma and 3 benign). Segmentectomy was done in 3 (1 colorectal liver metastasis, 2 HCC with CLD)

The final biopsy was malignancy in 12 patients. Two (2/12, $16.6 \%$ ) of them had a positive resection margin). Five patients (5/ 17, 29\% with preoperative suspicion of malignancy had a benign etiology (1 adenoma, 2 tuberculosis, 2 granular cell tumor) on final histopathology. 

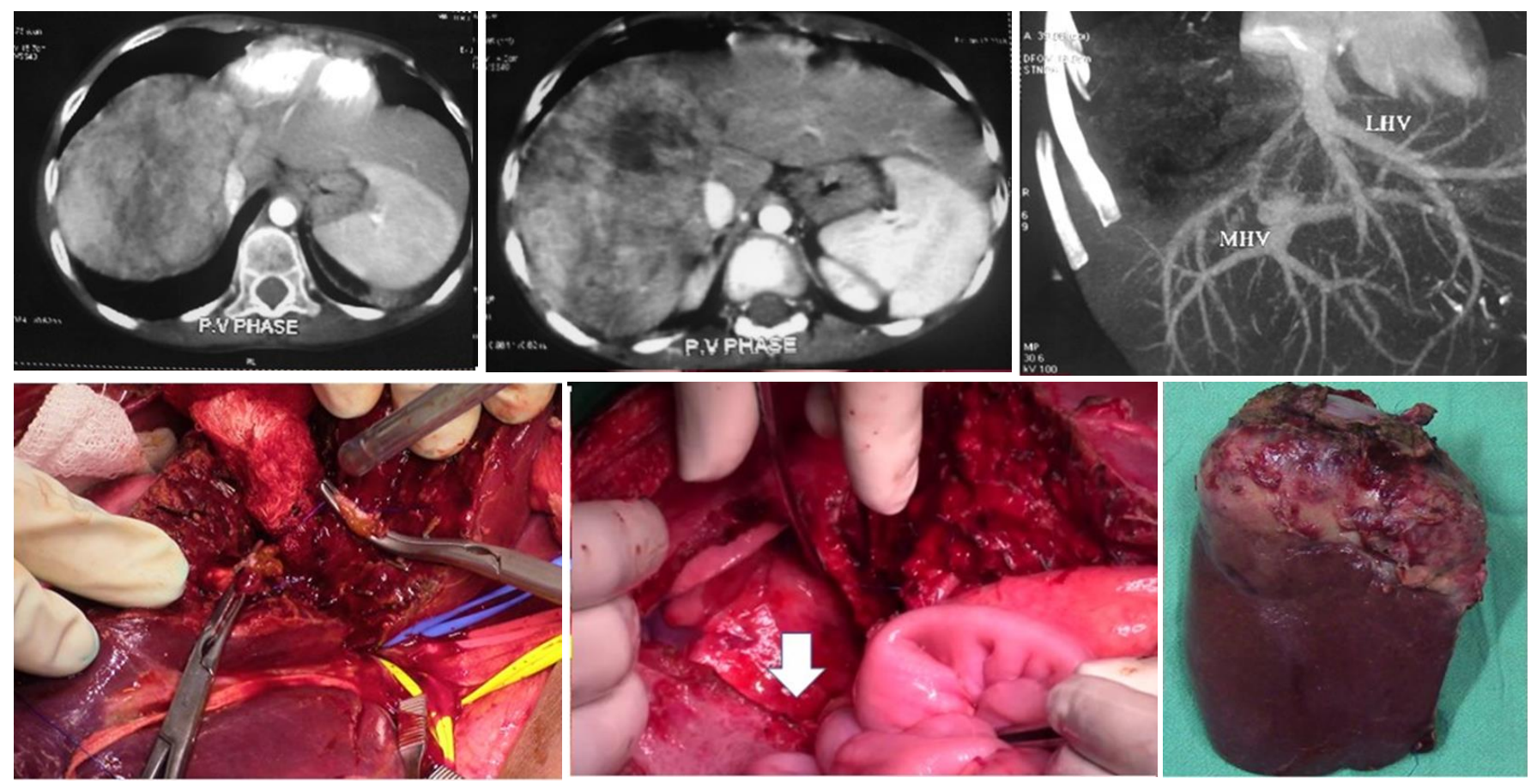

Fig 1: Hepatoblastoma post chemotherapy status. Tumor infiltrating diaphragm. Tumor was abutting left hepatic vein. Excision of diaphragm (white arrow) and right trisectionectomy was done

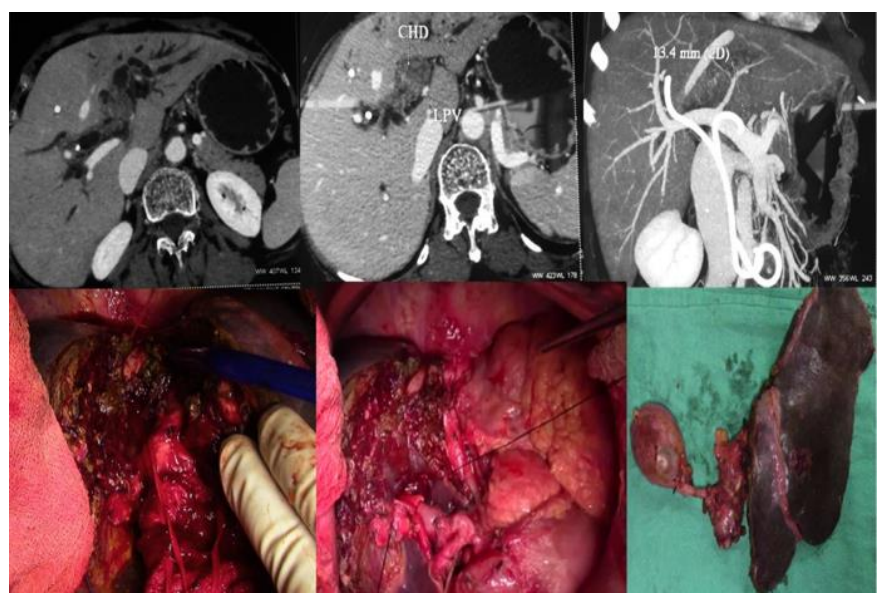

Fig 2: Hilar cholangiocarcinoma close to portal vein bifurcation with left lobe atrophy. Left hepatectomy, caudate lobe resection and bile duct excision was done

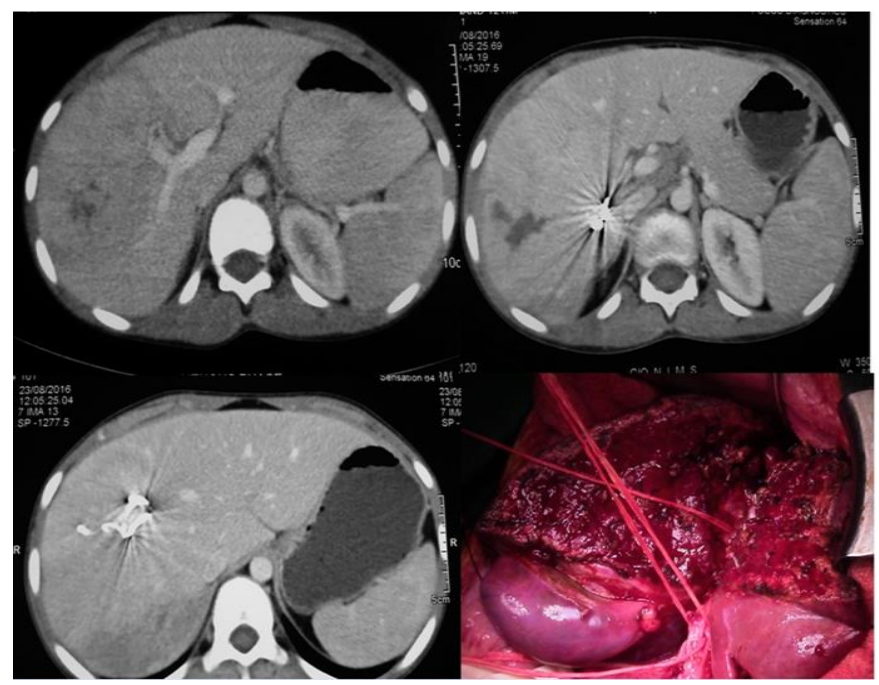

Fig 3: HCC close to portal vein and LHV. Right trisectionectomy done after portal vein embolization. The parenchymal transection was completed after inflow

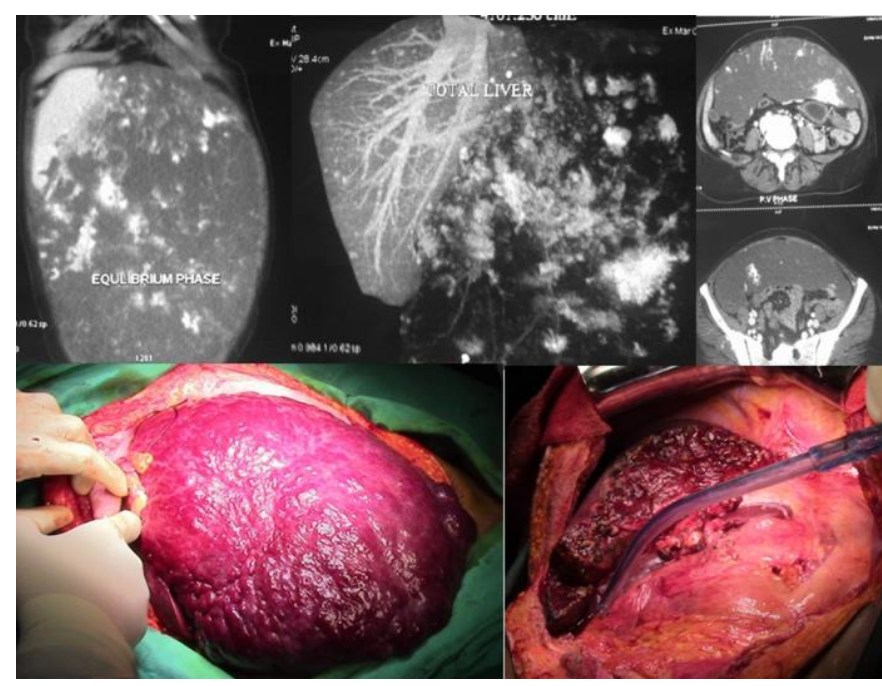

Fig 4: Giant hemangioma abutting MHV and reaching up to pelvis

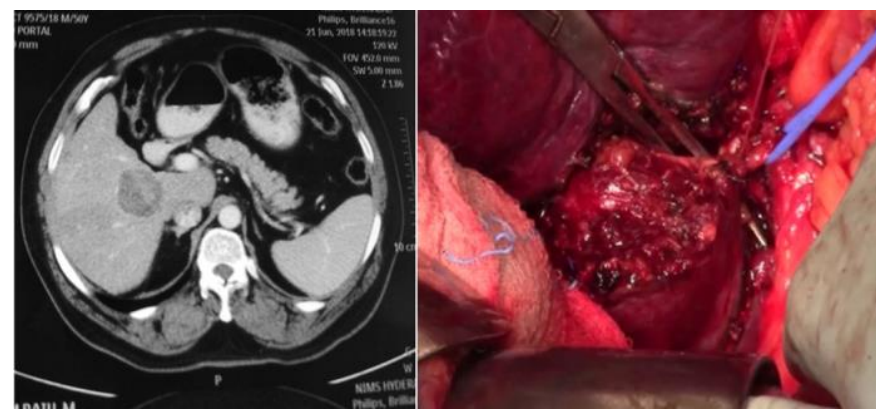

Fig 5: Segment 5 resection preserving right posterior pedicle

\section{Discussion}

In the present study of 23 patients with tumors close to major vessels of FLR we could achieve resection with a reasonable morbidity and mortality $(1 / 23,4.3 \%)$.

In assessing resectability considerable caution should be exercised before declaring a patient to be inoperable ${ }^{[8]}$. In majority of cases resection is the only option which can achieve 
the best results. Even invasion of hilar structures like portal vein or hepatic artery is not a contraindication for surgery ${ }^{[9]}$. Very large tumors or slow growing tumors near vessels may push the structures and because of pressure changes may mimic invasion $^{8}$. Tumors that expand and compress surrounding tissues (pushing tumors) and tumors that are pedunculated and attached to the liver by a base of narrow width (hanging tumors) are almost always resectable, and they should be distinguished from tumors that are irregular at the margins and clearly invasive ${ }^{[10]}$. We could resect majority of tumors without vascular resection. One patient with hilar cholangiocarcinoma had radial tumor margin positive and another one with hepatoblastoma had margin positive along LHV. The remaining patients could undergo resection with negative margins. In hilar cholangiocarcinoma vascular resection may have prevented a tumor margin positivity ${ }^{[11]}$. In hepatoblastoma the survival was comparable in $\mathrm{R} 1$ and $\mathrm{R} 0$ groups provided postoperative chemotherapy is given ${ }^{[12]}$. In our case the patient received preoperative chemotherapy and the tumor was very close to LHV insertion to IVC which is the only drainage to the FLR. Hence $\mathrm{R} 0$ resection could not be achieved.

In our study after obtaining inflow control the parenchymal transection was done and inflow ligated and cut only after the major vessels to FLR are intact. This approach avoids taking an irreversible step before completely assessing resectability. Such an approach was described for perihilar tumors [13]. We performed parenchymal transection with CUSA. We used intraoperative ultrasound if required. In patients with insufficient FLR, techniques like portal vein embolization ${ }^{[1]}$ can be used to increase the FLR. In our study one patient underwent surgery after portal vein embolization.

Some benign tumors can also pose technical challenges. In our study 2 patients with haemangioma underwent hepatectomy (one after attempted enucleation, one giant hemangioma). In general, only in selected patients with symptomatic haemangiomas (after carefully ruling out other causes of symptoms) should be considered for surgery. If surgery is done enucleation should be preferred over resection as the former has less blood loss and lesser complications ${ }^{[14]}$. However resection has a role as inflow occlusion of haemangioma will devasularise the hemangioma and useful in selected cases. Large biliary cystadenoma which are centrally located caused Grade III/IV complications in $45.2 \%$ of patients ${ }^{[15]}$. Two of our patients with large biliary cystadenoma underwent central hepatectomy and had an uneventful postoperative course.

Seven patients in our series had a large SOL $(>9 \mathrm{~cm})$ of liver with preoperative diagnosis of HCC or atypical HCC. One patient underwent 2 stage hepatectomy because of hemodynamic instability. In tumors close to the drainage of hepatic veins surgery should be done with utmost caution. Many of our cases had abutment to hepatic veins and IVC. Access to the supradiaphragmatic IVC can also be obtained through an abdominal incision by incising the central tendon of the diaphragm and incising the pericardium to expose the IVC as it enters the right atrium. In a study of 34 cases of liver resection with diaphragm excision showed comparable morbidity and mortality to patients who do not require diaphragm excision ${ }^{[16]}$. However, they have less favourable survival rates. In our study one patient required diaphragm excision due to infiltration. It also gave excellent access to suprahepatic IVC. One patient with tuberculosis masqueraded as large $\mathrm{HCC}$ on imaging. It is worthwhile to perform biopsy if atypical features are present on imaging ${ }^{[17]}$. Large adenomas require resection as they have potential for rupture and malignancy ${ }^{[18]}$. We operated one case of large Hepatic adenoma.

The tumor abutment to MHV may require it to be resected depending on the site of involvement. MHV anatomy is essential in deciding the type of liver resection ${ }^{[19,20]}$. Resecting part of MHV and preserving the distal part to preserve drainage of Segment V4 sup is essential in some cases. Partial MHV resection was done in 2 cases.

Segmentectomy was done in 3 (1 colorectal liver metastasis, 2 HCC with CLD) cases in our series. We used ultrasound assistance if required. Knowledge of anatomy and meticulous dissection is required to prevent inflow of FLR when segmentectomy is performed ${ }^{[21]}$.

All patients with hilar stricture with mass underwent a successful resection with no mortality and minimal morbidity. All patients underwent preoperative biliary drainage and optimised before surgery. Every effort was made to obtain a preoperative diagnosis in theses patient. However the incidence of benign lesions are more than reported in literature ${ }^{[22,23]}$. This can be attributed to small numbers and also to prevalence of parasitic infections and tuberculosis in India. More efforts need to be placed to decrease the incidence of benign conditions in patients undergoing major resections.

\section{Conclusion}

Tumors close to inflow or outflow of FLR can be resected with acceptable morbidity and mortality.

\section{References}

1. Makuuchi M, Thai BL, Takayasu K et al. Preoperative portal embolization to increase safety of major hepatectomy for hilar bile duct carcinoma: a preliminary report. Surgery. 1990; 107:521-527.

2. Are C, Gonen M, Zazzali K et al. The impact of margins on outcome after hepatic resection for colorectal metastasis. Ann Surg. 2007; 246:295-300.

3. Lim C, Mise Y, Sakamoto Y et al. Above $5 \mathrm{~cm}$, size does not matter anymore in patients with hepatocellular carcinoma. World J Surg. 2014; 38:2910-2918.

4. Poon RT, Fan ST, Wong J. Selection criteria for hepatic resection in patients with large hepatocellular carcinoma larger than $10 \mathrm{~cm}$ in diameter. J Am Coll Surg. 2002; 194:592-602.

5. Ho MC, Hasegawa $\mathrm{K}$, Chen XP et al. Surgery for Intermediate and Advanced Hepatocellular Carcinoma: A Consensus Report from the 5th Asia-Pacific Primary Liver Cancer Expert Meeting (APPLE 2014). Liver Cancer. 2016; 5:245-256.

6. Pawlik TM, Scoggins CR, Zorzi D et al. Effect of surgical margin status on survival and site of recurrence after hepatic resection for colorectal metastases. Ann Surg. 2005; 241:715-22, discussion.

7. Poultsides GA, Schulick RD, Pawlik TM. Hepatic resection for colorectal metastases: the impact of surgical margin status on outcome. HPB (Oxford). 2010; 12:43-49.

8. Blumgart's Text book of the Liver, Biliary tract and Pancreas, 2016.

9. Abbas S, Sandroussi C. Systematic review and metaanalysis of the role of vascular resection in the treatment of hilar cholangiocarcinoma. HPB (Oxford). 2013; 15:492503.

10. Baer HU, Gertsch P, Matthews JB et al. Resectability of large focal liver lesions. Br J Surg. 1989; 76:1042-1044.

11. Neuhaus $P$, Thelen A. Radical surgery for right-sided klatskin tumor. HPB (Oxford). 2008; 10:171-173. 
12. Daniel Aronson C, Víola Weeda B, Rudolf Maibach. Laurence Brugièreso for the Childhood Liver Tumour Strategy Group (SIOPEL). Microscopically positive resection margin after hepatoblastoma resection: what is the impact on prognosis? A Childhood Liver Tumours Strategy Group (SIOPEL) report. European journal of caner, 106, 126-132. 19 A.D. Ref Type: Journal (Full)

13. Kuriyama N, Isaji S, Tanemura A et al. Transhepatic Hilar Approach for Perihilar Cholangiocarcinoma: Significance of Early Judgment of Resectability and Safe Vascular Reconstruction. J Gastrointest Surg. 2017; 21:590-599.

14. Cheng WL, Qi YQ, Wang B et al. Enucleation versus hepatectomy for giant hepatic haemangiomas: a metaanalysis. Ann R Coll Surg Engl. 2017; 99:237-241.

15. Arnaoutakis DJ, Kim Y, Pulitano C et al. Management of biliary cystic tumors: a multi-institutional analysis of a rare liver tumor. Ann Surg. 2015; 261:361-367.

16. Li GZ, Turley RS, Lidsky ME et al. Impact of simultaneous diaphragm resection during hepatectomy for treatment of metastatic colorectal cancer. J Gastrointest Surg. 2012; 16:1508-1515.

17. Zorbas K, Koutoulidis V, Foukas $\mathrm{P}$ et al. Hepatic tuberculoma mimicking hepatocellular carcinoma in an immunocompetent host. BMJ Case Rep, 2013.

18. Dokmak S, Paradis V, Vilgrain V et al. A single-center surgical experience of 122 patients with single and multiple hepatocellular adenomas. Gastroenterology. 2009; 137:1698-1705.

19. Neumann JO, Thorn M, Fischer L et al. Branching patterns and drainage territories of the middle hepatic vein in computer-simulated right living-donor hepatectomies. Am J Transplant. 2006; 6:1407-1415.

20. Tani K, Shindoh J, Akamatsu N et al. Venous drainage map of the liver for complex hepatobiliary surgery and liver transplantation. HPB (Oxford). 2016; 18:1031-1038.

21. Yoshida H, Katayose Y, Rikiyama T et al. Segmentectomy of the liver. J Hepatobiliary Pancreat Sci. 2012; 19:67-71.

22. Otsuka S, Ebata T, Yokoyama Y et al. Benign hilar bile duct strictures resected as perihilar cholangiocarcinoma. $\mathrm{Br}$ J Surg. 2019; 106:1504-1511.

23. Anderson B, Doyle MBM. Surgical Considerations of Hilar Cholangiocarcinoma. Surg Oncol Clin N Am. 2019; 28:601-617. 